\title{
Assessment of Hemodynamic Changes and Complications Occurring with Propofol and Etomidate during General Anesthesia
}

\author{
Yashovardhan Singh ${ }^{1}$, Rohit Kumar Varshney ${ }^{2}$, Ravi Kumar Keshri ${ }^{1}$, G S Jheetay ${ }^{3}$ \\ 'Junior Resident, Department of Anaesthesia, TMMC \& RC, TMU, Moradabad, ${ }^{2}$ Associate Professor, Department of Anaesthesia, TMMC \& RC, TMU, \\ Moradabad, ${ }^{3}$ Professor \& Head, Department of Anaesthesia, TMMC \& RC, TMU, Moradabad.
}

\section{Abstract}

Background: Among general anesthesia induction drugs, etomidate is the only imidazole, and it has the most favorable therapeutic index for single bolus administration. Propofol has been shown in clinical studies to be a safe, effective, hypnotic, and amnesic anesthetic agent at induction doses of $2-2.5 \mathrm{mg} / \mathrm{kg}$ and maintenance doses of approximately $9 \mathrm{mg} / \mathrm{kg}$ per hour. Hence; we assessed hemodynamic changes and complications occurring with Propofol and Etomidate during general anesthesia. Subjects and Methods: A total of 100 subjects were enrolled in the present study and were broadly and randomly divided two study groups with 50 subjects in each group: Group A: Subjects who received $1 \%$ Propofol injection, and Group B: Subjects who received $0.3 \mathrm{mg} / \mathrm{kg}$ of etomidate injection. Monitoring of the blood pressure, mean arterial pressure and heart rate was done throughout the surgery and until 10 minutes after induction. Recording of the pain during injection was done on a scale of 0 to 10 with 0 referring to no pain while 10 referring to maximum pain. Results: No significant difference was observed while comparing the mean arterial pressure and heart rate among subjects of both the study groups at different time intervals except for at the time of induction. Mean pain score was found to be significantly higher in group A in comparison to group B. Conclusion: Among patients with associated altered hemodynamic status, etomidate is an improved option. However; further studies are recommended.

Keywords: Etomidate, Hemodynamic, Propofol

Corresponding Author: Dr. Rohit Kumar Varshney, Associate Professor, Department of Anaesthesia, TMMC \& RC, TMU, Moradabad, U.P., India.

Received: April 2018

Accepted: May 2018

\section{Introduction}

Among general anesthesia induction drugs, etomidate is the only imidazole, and it has the most favorable therapeutic index for single bolus administration. It also produces a unique toxicity among anesthetic drugs-- inhibition of adrenal steroid synthesis that far outlasts its hypnotic action and that may reduce survival of critically ill patients. ${ }^{[1-3]}$ The major molecular targets mediating anesthetic effects of etomidate in the central nervous system are specific $\gamma$ aminobutyric acid type A receptor subtypes. Propofol has been shown in clinical studies to be a safe, effective, hypnotic, and amnesic anesthetic agent at induction doses of $2-2.5 \mathrm{mg} / \mathrm{kg}$ and maintenance doses of approximately $9 \mathrm{mg} / \mathrm{kg}$ per hour. ${ }^{[4-6]}$ Hence; under the light of above mentioned data, we planned the present study to assess hemodynamic changes and complications occurring with Propofol and Etomidate during general anesthesia.

\section{Subjects and Methods}

The present study was conducted in the department of general anesthesia of the medical institute and it included assessment of hemodynamic changes and complications occurring with Propofol and Etomidate during general anesthesia. Ethical approval was obtained from institutional ethical committee and written consent was obtained after explaining in detail the entire research protocol. A total of 100 subjects were enrolled in the present study. Inclusion criteria for the present study included:

Subjects within the age group of 20 to 60 years,

Subjects with negative history of any other systemic illness, Subjects with negative history of any known drug allergy After meeting the inclusion criteria, all the 100 subjects were broadly and randomly divided two study groups with 50 subjects in each group:

Group A: Subjects who received 1\% Propofol injection, and Group B: Subjects who received $0.3 \mathrm{mg} / \mathrm{kg}$ of etomidate injection.

Detailed demographic data of all the patients was obtained. Complete haematological and biochemical analysis of all the patients was carried out. In all the subjects, premedication was done with alprazolam tablets and ranitidine tablets. Recording of the baseline hemodynamic values was done in all the patients, after they entered operation theatre. Recording of the time of induction and patient's myoclonic activity was done. Monitoring of the blood pressure, mean arterial pressure and heart rate was done throughout the surgery and until 10 minutes after induction. Recording of 
the pain during injection was done on a scale of 0 to 10 with 0 referring to no pain while 10 referring to maximum pain. Recording of all the results was done in Microsoft excel sheet followed by analysis by SPSS software. Chi- square test was used for assessment of level of significance. P-value of less than 0.05 was taken as significant.

\section{Results}

In the present study, a total of 100 subjects were enrolled and were broadly divided into two study groups with 50 patients in each group. Mean age of the patients of the group A and group B was 29.5 years and 30.1 years respectively. Mean weight of the patients of the group A and group B was 65.8 and $66.1 \mathrm{Kg}$ respectively. There were 30 males and 20 females in the group A while there were 28 males and 22 females in the group B. [Table 1] shows the mean hemodynamic parameters at different time intervals. No significant difference was observed while comparing the mean arterial pressure and heart rate among subjects of both the study groups at different time intervals except for at the time of induction. Mean pain score was found to be significantly higher in group A in comparison to group B.

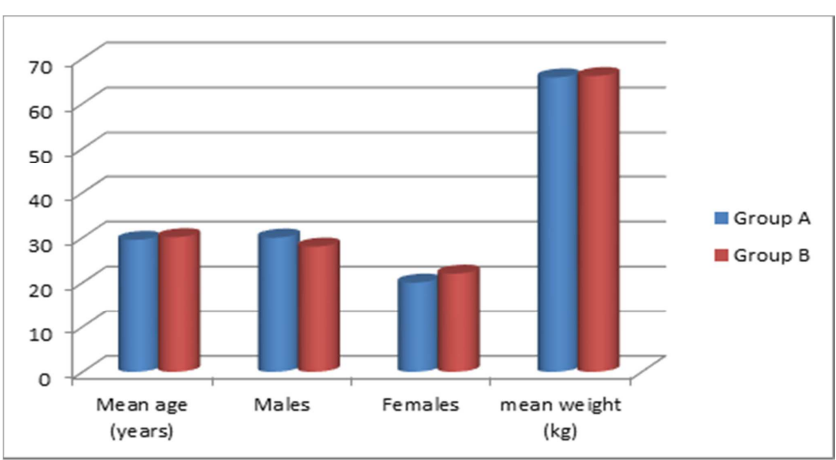

Figure 1: Demographic data

\begin{tabular}{l}
\hline Table 1: Mean hemodynamic parameters \\
\begin{tabular}{|l|l|l|l|l|}
\hline $\begin{array}{l}\text { Mean } \\
\text { parameter }\end{array}$ & hemodynamic & Group A & Group B & p- value \\
\hline $\begin{array}{l}\text { Mean } \\
\text { arterial } \\
\text { pressure }\end{array}$ & Baseline & 88.8 & 90.8 & 0.58 \\
\cline { 2 - 5 } & Induction & 79.5 & 87.25 & $\begin{array}{l}0.00 \\
\text { (Significant) }\end{array}$ \\
\cline { 2 - 5 } & $\begin{array}{l}\text { At 10 } \\
\text { minutes }\end{array}$ & 95.8 & 96.4 & 0.44 \\
\hline \multirow{2}{*}{ Heart rate } & Baseline & 83.1 & 85.1 & 0.82 \\
\cline { 2 - 6 } & Induction & 99.1 & 97.5 & 0.46 \\
\cline { 2 - 5 } & $\begin{array}{l}\text { At } 10 \\
\text { minutes }\end{array}$ & 80.2 & 81.8 & 0.38 \\
\hline
\end{tabular}
\end{tabular}

Table 2: Pain

\begin{tabular}{|l|l|l|l|}
\hline Parameter & Group A & Group B & p- value \\
\hline Mean pain score & 1.5 & 0.7 & 0.00 \\
\hline
\end{tabular}

\section{Discussion}

Few of the side effects that occur with Propofol are blood pressure drop, ventilation depression in a dose dependent manner and pain during injection. ${ }^{[4]}$ Etomidate has a special property of its hemodynamic stability. It causes minimal respiratory depression and hascerebral protective actions. ${ }^{[7-9]}$
In the present study, a total of 100 subjects were enrolled and were broadly divided into two study groups with 50 patients in each group. Mean age of the patients of the group A and group B was 29.5 years and 30.1 years respectively. Mean weight of the patients of the group A and group B was 65.8 and $66.1 \mathrm{Kg}$ respectively. There were 30 males and 20 females in the group A while there were 28 males and 22 females in the group $B$. Mayer $M$ et al compared the haemodynamic effects, the patients' sensations, signs of thrombophlebitis and postoperative nausea and vomiting (PONV) following injection of both drugs. Following premedication with $2 \mathrm{mg}$ Lormetazepam p.o. in 50 patients per group, anaesthesia was induced with either $0.51 \mathrm{mg}$ etomidate in lipid emulsion or $3.04 \mathrm{mg}$ propofol per $\mathrm{kg}$ bw. No opioid or benzdiazepine was given i.v. before induction. After injection of the tested drug, the cannula was removed. Changes in blood pressure and heart rate were recorded as well as signs of discomfort during and after injection (pain, burning, tension, cold). Venous sequelae were assessed for 5 days after injection to register signs of thrombophlebitis. Demographic data showed no difference between the two groups. After propofol more often a fall in blood pressure was seen. Pain ( 25 vs 1 pt), burning 19 vs 1 ), tension 15 vs 3 ), cold (35 vs 17) after injection was registered significantly more often in the propofol group, whereas myocloni predominated in the etomidate group (13 vs 6$) \mathrm{P}<0.05$, chisquared-test). No difference was seen in PONV in either groups. Etomidate formulated in a medium chain lipid emulsion causes significant less discomfort for the patients than propofol, which is solved in a long chain formulation. Myocloni, however, occur significantly more frequently after etomidate than after propofol. ${ }^{[10]}$

[Table 1] shows the mean hemodynamic parameters at different time intervals. No significant difference was observed while comparing the mean arterial pressure and heart rate among subjects of both the study groups at different time intervals except for at the time of induction. Mean pain score was found to be significantly higher in group A in comparison to group B. Aggarwal S et al compared propofol and etomidate for their effect on hemodynamics and various adverse effects on patients in general anesthesia. Hundred ASA I and II patients of age group 18-60 years scheduled for elective surgical procedure under general anesthesia were randomly divided into two groups of 50 each receiving propofol $(2 \mathrm{mg} / \mathrm{kg})$ and etomidate $(0.3 \mathrm{mg} / \mathrm{kg})$ as an induction agent. Vital parameters at induction, laryngoscopy and thereafter recorded for comparison. Adverse efafect viz. pain on injection, apnea and myoclonus were carefully watched. Demographic variables were comparable in both the groups. Patients in etomidate group showed little change in mean arterial pressure (MAP) and heart rate (HR) compared to propofol $(p>0.05)$ from baseline value. Pain on injection was more in propofol group while myoclonus activity was higher in etomidate group. This study concluded that etomidate is a better agent for induction than propofol in view of hemodynamic stability and less pain on injection. ${ }^{[1]}$

\section{Conclusion}


Under the light of above obtained results, the authors conclude that among patients with associated altered hemodynamic status, etomidate is an improved option. However; further studies are recommended.

\section{References}

1. Godefroi EF, Janssen PAJ, Van der Eycken CAM, Van Heertum AHMT, Niemegeers CJE. DL-(1-arylalkyl)imidazole-5-carboxylate esters. A novel type of hypnotic agents. J Med Chem. 1965;56:220-223.

2. Husain SS, Ziebell MR, Ruesch D, Hong F, Arevalo E, Kosterlitz JA, Olsen RW, Forman SA, Cohen JB, Miller KW. 2-(3-Methyl-3Hdiaziren-3-yl)ethyl 1-(1-phenylethyl)-1H-imidazole-5-carboxylate: A derivative of the stereoselective general anesthetic etomidate for photolabeling ligand-gated ion channels. J Med Chem. 2003;46:12571265.

3. Linton DM, Thornington RE. Etomidate as a rectal induction agent. Part II: A clinical study in children. S Afr Med J. 1983;64:309-310.

4. Latson TW, McCarroll SM, Mirhej MA, Hyndman VA, Whitten CW, Lipton JM. Effects of three anesthetic induction techniques on heart rate variability. J Clin Anesth. 1992;4:265-276.
5. Janssen PA, Niemegeers CJ, Marsboom RP. Etomidate, a potent nonbarbiturate hypnotic: Intravenous etomidate in mice, rats, guinea-pigs, rabbits and dogs. Arch Int Pharmacodyn Ther. 1975;214:92-132.

6. Morgan M, Lumley J, Whitwam JG. Etomidate, a new water-soluble non-barbiturate intravenous induction agent. Lancet. 1975;321:955-956.

7. Doenicke A, Roizen MF, Nebauer AE, Kugler A, Hoernecke R, BegerHintzen H. A comparison of two formulations for etomidate, 2hydroxypropyl-beta-cyclodextrin (HPCD) and propylene glycol. Anesth Analg. 1994;79:933-939.

8. Kay B. Total intravenous anesthesia with etomidate part II: Evaluation of a practical technique for children. Acta Anaesthesiol Belg. 1977;28:115-121.

9. Streisand JB, Jaarsma RL, Gay MA, Badger MJ, Maland L, Nordbrock E, Stanley TH. Oral transmucosal etomidate in volunteers. Anesthesiology. 1998;88:89-95.

10. Mayer M1, Doenicke A, Nebauer AE, Hepting L. Propofol and etomidate-Lipuro for induction of general anesthesia. Hemodynamics, vascular compatibility, subjective findings and postoperative nausea. Anaesthesist. 1996 Nov;45(11):1082-4.

11. Aggarwal S1, Goyal VK2, Chaturvedi SK1, Mathur V1, Baj B1, Kumar A1. A comparative study between propofol and etomidate in patients under general anesthesia. Braz J Anesthesiol. 2016 May-Jun;66(3):23741. doi: 10.1016/j.bjane.2014.10.005. Epub 2015 May 12.

Copyright: () the author(s), publisher. Academia Anesthesiologica International is an Official Publication of "Society for Health Care \& Research Development". It is an open-access article distributed under the terms of the Creative Commons Attribution Non-Commercial License, which permits unrestricted non-commercial use, distribution, and reproduction in any medium, provided the original work is properly cited.

How to cite this article: Singh Y, Varshney RK, Keshri RK, Jheetay GS. Assessment of Hemodynamic Changes and Complications Occurring with Propofol and Etomidate during General Anesthesia. Acad. Anesthesiol. Int. 2018;3(2):31-33.

DOI: dx.doi.org/10.21276/aan.2018.3.2.8

Source of Support: Nil, Conflict of Interest: None declared. 